\title{
Clinico-Demographic Profile and Management Outcomes of Patients With Ocular Surface Squamous Neoplasia in a Tertiary Eye Care Hospital in Nepal
}

\section{Nisha Shrestha}

Tilganga Institute of Ophthalmology

Purnima Rajkarnikar Sthapit ( $\sim$ purnimark@gmail.com )

Tilganga Institute of Ophthalmology https://orcid.org/0000-0001-5210-7318

Rohit Saiju

Tilganga Institute of Ophthalmology

\section{Research article}

Keywords: CIN, Invasive squamous cell carcinoma of conjunctiva, Mitomycin, Interferon alfa 2B

Posted Date: December 30th, 2020

DOl: https://doi.org/10.21203/rs.3.rs-136107/v1

License: (c) (1) This work is licensed under a Creative Commons Attribution 4.0 International License.

Read Full License 


\section{Abstract}

Background: To evaluate the Clinico-demographic profile and management outcomes of patients with Ocular Surface Squamous Neoplasia (OSSN) in a tertiary eye care hospital in Nepal

Methods: All the patients with biopsy proven OSSN presenting to Oculoplasty and Ocular Oncology department of Tilganga Institute of Ophthalmology, Nepal over 1 year were retrospectively studied for clinical and demographic profiles, medical and surgical management and the outcomes of the management.

Results: A total of 39 eyes of 37 patients were included in this study. The average age of patients was 44.56 years (range- 15 years to 84 years) consisting of $21(56.8 \%)$ male and $16(43.2 \%)$ female. The ration of participating male and female patients (M:F) was 1.31:1. 35 cases $(94.6 \%)$ were unilateral whereas 2 cases with Xeroderma pigmentosa had bilateral involvement. Nasal bulbar conjunctiva in (43.58\%) was the most common. 6 (16.2\%), 19 (51.4\%) and 12 (32.4\%) patients received primary medical management alone, surgical management alone and both surgical and adjuvant medical managements respectively.

Histologically, the most common finding was CIN I with 10 (31.25\%) patients. Surgical margins were free in 15 eyes $(46.87 \%)$, whereas 17 eyes $(53.12 \%)$ had one or more margins involved and hence, they received adjuvant topical chemotherapy. Moreover, 5 (15.38\%) out of 39 eyes had recurrence.

Conclusion: OSSN is usually present in middle age group though it may occur early and become rapidly progressive as in the cases of Xeroderma pigmentosa. Recurrence after surgery can occur despite optimal management.

\section{Background}

Ocular Surface Squamous Neoplasia (OSSN) is a term that incorporates pre-cancerous and cancerous epithelial lesions of the conjunctiva and cornea. It includes Dysplasia, Conjunctival intraepithelial neoplasia (CIN) and Invasive Squamous cell carcinoma (SCC). ${ }^{[1-4]}$

Reported worldwide incidence of OSSN ranges between $0.02-3.5$ cases per 100,000 people. OSSN is mostly unilateral and the incidence is strongly associated with exposure to ultraviolet radiation, human immunodeficiency virus (HIV) infection, human papillomavirus infection, ${ }^{[2,5,6,7,8]}$ heavy cigarette smoking, ${ }^{[9,10]}$ male gender and age. The average age of presentation is usually the sixth and seventh decades of life. However, in immunocompromised individuals, OSSN may occur at a younger age. $[4,5]$ Several cases of OSSN have been reported after chronic inflammatory diseases, such as benign mucous membrane pemphigoid ${ }^{[11]}$, chronic blepharoconjunctivitis ${ }^{[12]}$, leukemia ${ }^{[13]}$ and lymphoma ${ }^{[14]}$, and in a patient following liver transplantation ${ }^{[15]}$. Other etiologic factors associated to OSSN include ocular surface injury ${ }^{[16,17]}$, vitamin A deficiency ${ }^{[17]}$, and exposure to chemicals and drugs such as trifluridine ${ }^{[18]}$. Xeroderma pigmentosum is another rare systemic condition which leads to OSSN in younger age 
group. The involvement is usually bilateral and seen more commonly in limbal area ${ }^{[6,9,19]}$. The prevalence of OSSN in XP ranges from 11-30\%. ${ }^{[19-20]}$

Lack of consistent clinical criteria increases complexity in distinguishing benign from malignant lesion. However rapidly growing ill or well -defined lesion with telengectactic vessels, intrinsic vascularity, keratin deposits on the surface and corneal extension and a nodular lesion raise suspicion of invasive SCC.

The management of OSSN involves surgical resection using the "no touch" technique with or without nonsurgical therapies including topical chemotherapy (mitomycin C, 5-fluorouracil), topical/injection immunotherapy (interferon alpha-2b). ${ }^{[10]}$ Plaque brachytherapy is an effective and well-tolerated modality for the management of patients with ocular surface malignancy with evidence of localized corneo- scleral invasion. ${ }^{[21]}$

Though a rare condition, the incidence of OSSN has been increasing in the developing countries in recent years. Our institute is also observing an increase in number of OSSN cases as all the suspected cases have proven with hisptopathological examination with each passing year. Thus, this study is our attempt to find out the detailed clinic - demographic profile and management outcome of OSSN presenting in tertiary eye care center of Nepal, Tilganga Institute of Ophthalmology. In contrast to the similar studies done in Nepal, this study has tried to go more into the details of the management outcomes in the OSSN patients

\section{Materials And Methods}

This is a retrospective study conducted on patients presented to the out-patient department of Oculoplasty and Ocular Oncology at Tilganga Institute of Ophthalmology, Kathmandu, Nepal over a period of 1 year (January to December 2018). A total of 39 eyes of 37 patients, clinically diagnosed as OSSN and later confirmed by histopathology were included in this study. A detailed history of the 37 patients were obtained including demography. Clinical features were evaluated including laterality, type of lesion, management plan (medical, surgical or both) and recurrence if any.

All the patients were advised for surgery as primary management. Consenting patients underwent surgery followed with Histopathological examination. Patients with any surgical margins positive for tumor cells were put on adjuvant medical management. Patients not consenting to surgery, medically unfit for surgery and patients with recurrence were put on medical management only.

For surgery, routine pre-operative investigations were done. A "no touch" technique was used to excise OSSN lesions. Conjunctival incision was made $4 \mathrm{~mm}$ outside the clinically determined tumor margin incorporating the full thickness of conjunctiva and tenons capsule. Absolute alcohol was then applied to the cornea to loosen the epithelium from the basement membrane, and then rinsed off with copious irrigation after 40 to 45 seconds. All involved corneal epithelium with $2 \mathrm{~mm}$ of clear cornea outside the visible lesion and any associated corneal pannus was then scraped off with a keratome. Then, using a double freeze- thaw technique, cryotherapy was applied to the conjunctival edges, involved limbal zone. 
Bare scleral bed cryotherapy (triple freeze and thaw technique) was also applied to the limbus when tumor was found adherent to the episclera or sclera. Excision was followed by direct closure or closure with autologous graft or with amniotic membrane graft depending upon the size of the lesion. The specimen was then put in the filter paper with marking marked medial, lateral, superior and inferior margins. The excised specimen was then sent for histopathological analysis. Post operatively, patients were prescribed antibiotic and steroid drops for 6 weeks along with tear supplements. Patients were analyzed according to histopathological reports, follow up pattern and recurrence. MMC $0.04 \%$ four times a day was started on all patients who had margins involved in the histopathology reports. MMC was started on " 1 week on" and " 1 week off" basis and was given for 4 cycles according to Will eye hospital protocol. Patients intolerant to MMC, were given Interferon alpha2B $1 \mathrm{millionlU} / \mathrm{ml}$ four times a day for two months based on availability.

All patients attending TIO with clinical diagnosis and/or histopathological diagnosis of OSSN were included in this study. Patients with follow up less than 6 months were excluded. Management outcome was evaluated in terms of remission of the tumor or recurrence.

Data was entered into an Excel sheet and analysis was done. Appropriate statistical tools were employed for test of significance.

This original article has been approved by the Tilganga Institute of Ophthalmology Institutional Review Committee and follows the tenets of declaration of the Helsinki of World Medical Association.

\section{Results}

A total of 39 eyes of 37 patients were included in the study. The mean age of the patients was 44.56 years. The age range of the patients in this study was 15 years to 84 years. Majority of the patients in this study were in 4th decade of life and the lowest number of OSSN was seen in patients in their 8th decade of life. Number of males in this study was 21(56.8\%) and that of females was 16(43.2\%); M:F ratio being 1.31:1. Out of 37 patients included in this study, 30 (81.1\%) were from hilly region, $4(10.8 \%)$ from the terai of Nepal and 1 (2.7\%) from mountains of Nepal and 2 (5.4\%) were from India. Most of the cases $(94.6 \%, 35$ patients) showed unilateral involvement whereas, there were 2 cases with Xeroderma Pigmentosa with bilateral involvement. In unilateral cases, higher occurrence was observed in right eye compared to left eye (20 cases RE vs. 15 cases LE). 17 out of 39 eyes (43.58\%) had nasal, 13 (33.33\%) had temporal involvement, $4(10.25 \%)$ had superior, $2(5.12 \%)$ had inferior and $3(7.69 \%)$ had diffuse lesion. $6(16.2 \%)$ patients underwent primary medical management alone, $19(51.4 \%)$ patients underwent surgical management alone and $12(32.4 \%)$ patients underwent both surgical and adjuvant medical management.

Out of 18 patients who received medical treatment, 13(72.2\%) were treated with MMC alone whereas in 5 $(27.7 \%)$ cases, it was switched to INF after second or third cycle of MMC because of intolerance. Among the 30 patients undergoing surgery, 10 (33.33\%) underwent excision biopsy alone (due to unavailability of cryotherapy at that time), 15 (50\%) underwent excision biopsy with cryotherapy with autologous graft, 
$3(10 \%)$ underwent excision biopsy with cryotherapy with amniotic membrane graft and 2(6.6\%) patients with diffuse neoplasia involving the extraocular muscles and tenons underwent exenteration. On histological examination of 32 eyes of 30 patients who underwent excisional biopsy surgery, the most common histopathological finding was CIN I in 12 eyes (37.5\%). Rest of the report is shown in Table 2. Surgical margin came out to be free in 15 eyes $(46.87 \%)$ whereas 17 eyes $(53.12 \%)$ had one or more margins involved and hence they received adjuvant topical chemotherapy. 5 (12.8\%) out of 39 eyes had recurrence. Among the recurrent cases 2 had CIS, 1 had CIN III, 1 had CIN II and 1 had CIN I. Time to recurrence was 9 months in 3 patients, 12 months in 1 and 15 months in 1 patient following the completion of treatment. 
Table 1

Patients Clinico-Demography

\begin{tabular}{|ll|}
\hline PARAMETERS & STUDY POPULATION \\
& $\mathbf{N}=39$ eyes of 37 people \\
\hline AGE (MEAN 44.56) & $13(35.13 \%)$ \\
40 years or less & $24(64.86 \%)$ \\
$<40$ years & \\
\hline GENDER (M:F = 1.31:1) & $16(43.24 \%)$ \\
Male & $21(56.75 \%)$ \\
Female & \\
\hline ADDRESS & $30(81.1 \%)$ \\
Hilly region & $1(2.8 \%)$ \\
Mountain region & $4(10.8 \%)$ \\
Terai region & $2(5.4 \%)$ \\
India & \\
\hline LATERALITY OF TUMOR & $35(94.6 \%)$ \\
Unilateral & $2(5.4 \%)$ \\
Bilateral & \\
\hline LOCATION OF TUMOR & $17(44 \%)$ \\
Nasal & $13(33 \%)$ \\
Temporal & $4(10 \%)$ \\
Superior & $2(5 \%)$ \\
Inferior & $3(8 \%)$ \\
Diffuse & \\
\hline
\end{tabular}


Table 2

Histopathological types

\begin{tabular}{|ll|}
\hline Histopathological grading & Number (\%) \\
\hline CIN I & $12(37 \%)$ \\
\hline CIN II & $9(28 \%)$ \\
\hline CIN III & $4(13 \%)$ \\
\hline CIS & $5(16 \%)$ \\
\hline SCC & $2(6 \%)$ \\
\hline
\end{tabular}

\section{Discussion}

The age range of patients of OSSN in this study ranges from 15 to 84 years with the mean age of 44.5 which is in accordance with other studies. ${ }^{[1]}$ However, the HIV positive individual and patients with systemic illness like Xeroderma Pigmentosum are seen to present at a younger age. ${ }^{[11]}$ The bilateral cases in this study were of Xeroderma Pigmentosum and both presented at a relatively young ages of 19 and 22 years. None of our patients were positive for HIV.

Slight male preponderance was seen with M:F ratio 1.3:1, which is similar to other studies. ${ }^{[1,21,22]}$ It has been observed that male gender is a likely risk factor for higher preponderance as they are more commonly employed in professions involving outdoor work thereby leading to increased exposure to UV$B$ rays which is a known risk factor for development of OSSN. ${ }^{[1,21,22,23,24]}$ The majority of lesions in our study occurred in nasal and temporal areas which are exposed to the highest amount of UV-B radiation, which is similar to other studies ${ }^{[6,23,24]}$. Most of our patients were also from hilly regions which has more UV-B exposure as compared to terai/flat region, which supports UV-B exposure as a risk factor OSSN. Mountain region with the most UV-B exposure among the three regions in Nepal is less populated which resulted in less patient from that area. Due to these factors we presume our findings support the fact that UV-B rays are strongly associated with the development of OSSN. However, the data on exposure was unavailable in our data set so this association is just speculative.

Most of the cases $(94.6 \%, 35$ patients) showed unilateral involvement whereas there were 2 cases with bilateral involvement. Both the bilateral cases in this study were known cases of XP and it has been well documented that patients with Xeroderma Pigmentosa are prone to develop OSSN and progress rapidly owing to the defective DNA repair. $[6,9,19]$

Topical therapies for OSSN has rapidly grown in popularity in recent years, yet surgical excision remains the most important treatment option in the management of OSSN, as it provides a pathological diagnosis, differentiates it from masquerading lesions, decreases the tumor load and can diagnose invasion, which would necessitate a different treatment approach. Majority of the patients in our study underwent wide excision with cryotherapy (with autologous graft or with AMG). Some had excision of the 
OSSN due to unavailability of the cryotherapy at the given moment. All the patients with evidence of tumor cells in any margins were put on adjuvant chemotherapy as it has shown to decrease the recurrence. 2 patients underwent exenteration due to extension of the tumor to the tenon and sclera.

Various factors for tumor recurrence include systemic illness like HIV and XP, presence of persistent ocular surface irritating factors, involvement of the tarsus and positive surgical margins, of which the latter two were found to be the strongest predictors for clinical recurrence. ${ }^{[23]}$ Recurrence rates following excision of OSSN alone range from $5-69 \%{ }^{[25-28]}$ and after excision combined with cryotherapy range from $7.7-11.5 \% .{ }^{[29-30]}$ The lower rates of recurrence are seen in cases where the margins of the excised specimen were free of tumor cells and adjuvant chemotherapy has been used and the higher rates when dysplastic tissue was left at the surgical margins and in more advanced lesions. ${ }^{[25,26,27,28,31]}$ Therefore, it is very important to ensure clear surgical margins. Our study had $12.8 \%$ recurrence rate which is similar

to other studies. ${ }^{[31,32]}$ Though our data on recurrence is low, we observed that 3 out of 5 recurrence were managed initially with excision biopsy only and 2 were managed with excision biopsy with cryotherapy with AMG. Similarly, 4 out of 6 recurrences had histological grading CIN III to SCC and 5 out of 6 cases with recurrence had positive surgical margins for tumor cells. So, the higher grades of OSSN in our patients and lack of cryotherapy could be the factors for the higher rate of recurrence in this study but the major factor can be attributed to the involvement of margins. The mean duration to recurrence in our study was 9 months following the completion of the treatment which was similar to other studies that state most recurrence took place within 2 years after primary excision. ${ }^{[33,34]}$ Consistent with a study done in $\mathrm{UK}^{[32]}$ age and sex of the patient didn't show any significant role in the recurrence.

\section{Conclusion}

OSSN is usually present in middle age group though it may occur early and become rapidly progressive in cases of Xeroderma pigmentosa. Wide margin excisional biopsy and cryotherapy to the base and margins is the management of choice for OSSN involving less than 2 quadrants. Recurrence after surgery can occur despite optimal management. Though slow growing in nature, advanced invasive lesions may end up in mutilating surgery like exenteration. It is recommended to do the biopsy on all the suspicious limbal and perilimbal lesions presenting to the clinics.

\section{Declarations}

- Ethics approval and consent to participate: name of the ethics committee that approved the study and the committee's reference number if appropriate

- Consent for publication:

- Availability of data and materials

- Competing interests: The authors declare that they have no competing interests

- Funding: None 
- Authors' contributions: All authors read and approved the final manuscript

- Acknowledgements:

- Authors' information (optional)

\section{References}

1. Shields C, Shileds JA. Tumors of the conjunctiva and cornea. Surv Ophthalmol. 2004;49(1):3-24.

2. Lee G, Hirst LW. Ocular surface squamous neoplasia. Surv Ophthalmol. 1995;39(6):429-50.

3. Pe'er J. Ocular surface squamous neoplasia. phthalmol Clin North Am. 2005;18(1):1-13.

4. Shields C, Kaliki S, Kim HJ, Al-Dahmash S, Shah SU, Lally SE, Shields JA. Interferon for ocular surface squamous neoplasia in 81 cases: outcomes based on the American Joint Committee on Cancer classification. Cornea. 2013;32(3):248-56.

5. Yang J, Stephen FC. Squamous cell carcinoma of the conjunctiva. . Int Ophthalmol Clin 1997;37(4):73-85.

6. Shields J, Shields CL. Eyelid, Conjunctival and Orbital Tumours. An Atlas and Textbook. 2nd ed. Philadelphia, PA: Lippincott Williams and Wilkins; 2008.

7. Shields C, Demirci H, Karatza, E, Shields JA. Clinical survey of 1643 melanocytic and nonmelanocytic conjunctival tumours. Ophthalmology. 2004;111(9):1747-54.

8. Dandala PP, Mallad A, Kavitha. Ocular Surface Squamous Neoplasia (Ossn): A Retrospective Study. Journal of Clinical and Diagnostic Research. 2015; 9(11): NC10-NC13

9. Porges Y, Groisman GM. Prevalence of HIV with conjunctival squamous cell neoplasia in an African provincial hospital. . Cornea. 2003;22(1):1-4.

10. Balint G. Situation analysis of HIV/AIDS epidemic in sub-saharan Africa. East Afr Med J. 1998;75:684-6.

11. Sivalingam V, Shields CL, Shields JA, Pearah JD. Squamous cell carcinoma of the conjunctiva associated with benign mucous membrane pemphigoid. Ann Ophthalmol 1990;22(3):106-9.

12. Akpek E, Polcharoen W, Chan R, Foster CS. Ocular surface neoplasia masquerading as chronic blepharoconjunctivitis. Cornea. 1999;18(3):282-8.

13. Heinz C, Fanihagh F, Steuhl KP. Squamous cell carcinoma of the conjunctiva in patients with atopic eczema. Cornea. 2003;22(2):135-7.

14. Awan K. Intraepithelial epithelioma (Bowen's disease) of the conjunctiva and chronic lymphocytic leukemia. Ann Ophthalmol. 1978;10(6):781-3.

15. Kushner F, Mushen RL. Conjunctival squamous cell carcinoma combined with malignant lymphoma. Am J Ophthalmol 1975;80(3):503-6.

16. Shelil A, Shields CL, Shields JA, Eagle RC. Aggressive conjunctival squamous cell carcinoma in a patient following liver transplantation. Arch Opthalmol. 2003;121(2):280-2.

17. Ash J, WIlder HC. Epithelial tumors of the limbus. Am J Ophthalmol. 1942;25:923-32. 
18. Maugdal P, Van Damme B, Missotten L. Corneal epithelial dysplasia after trifluridine use. Albrecht Von Graefes Arch Klin Exp Ophthalmol. 1983;220:6-12.

19. Goyal J, Srinivasan VAR, Agrawal K. Oculocutaneous manifestations in xeroderma pigmentosa. $\mathrm{Br} \mathrm{J}$ Ophthalmol. 1994;78(4):295-7.

20. Kraemer K, Lee MM, Scotto J. Xeroderma pigmentosum - cutaneous, ocular and neurologic abnormalities in 830 published cases. Arch Opthalmol. 1987;123:241-50.

21. Walsh-Conway N, Conway RM. Plaque brachytherapy for the management of ocular surface malignancies with corneoscleral invasion. Clin Exp Ophthalmol. 2009;37(6):577-83.

22. Gupta R. CLINICAL PROFILE OF OCULAR SURFACE SQUAMOUS NEOPLASIA (OSSN). International Journal of Medical and Biomedical Studies. 2019;3(6):1-3.

23. Kao A, Galor A, Karp CL, Abdelaziz A. Clinicopathologic Correlation of Ocular Surface Squamous Neoplasms at Bascom Palmer Eye Institute: 2001 to 2010. Ophthalmology. 2012;119(9):1773-6.

24. Galor A, Karp CL, Oellers P, Kao AA, Abdelaziz A, Feuer W, Dubvoy SR. Predictors of ocular surface squamous neoplasia recurrence after excisional surgery. Ophthalmology. 2012;119(10):1974-81.

25. Pe'er J. Ocular Surface Squamous Neoplasia. . International Ophthalmology Clinics. 2015;55(1):9-21.

26. Erie J, Campbell RJ, Liesegang J. Conjunctival and corneal intraepithelial and invasive neoplasia. . Ophthalmology. 1986;93:176-83.

27. Tabin G, Levin S, Snibson G, Loughan M, Taylor H. Late recurrences and the necessity for long-term follow-up in corneal and conjunctival intraepithelial neoplasia. Ophthalmology. 1997;104(3):485-92.

28. Nanji A, Moon CS, Galor A, Sein J, Oellers P, Karp CL. Surgical versus medical treatment of ocular surface squamous neoplasia: a comparison of recurrences and complications. Ophthalmology. 2014;121(5):994-1000.

29. Sudesh S, Rapuano CJ, Cohen EJ, Eagle J RC, Laosbon PR. Surgical management of ocular surface squamous neoplasms: the experience from a cornea center. Cornea. 2000;19(3):278-83.

30. Mirzayev I, Gunduz AK., Ates FSO, Ozxan G., Isik MU. Factors affecting recurrence after surgical treatment in cases with ocular surface squamous neoplasia. int Ophthalmol. 2019;12(9):1426-31.

31. Yousef $Y$, Finger, PT. Squamous carcinoma and dysplasia of the conjunctiva and cornea: an analysis of 101 cases. Ophthalmology. 2012;119(2):233-40.

32. Maudgil A, Patel T, Rundle P, Rennie IG, Mudhar HS. Ocular surface squamous neoplasia: analysis of 78 cases from a UK ocular oncology centre. British Journal of Ophthalmology. 2013;97(12):1520-4.

33. Kim B, Kim, MK., Wee, WR., Oh, JY. Clinical and pathological characteristics of ocular surface squamous neoplasia in an Asian population. Graefe's Archive for Clinical and Experimental Ophthalmology. 2013;251(11):2569-73.

34. Meel $R$, Dhiman $R$, Vanathi $M$, Pushker $N$, Tandon $R$, Devi S. Clinicodemographic profile and treatment outcome in patients of ocular surface squamous neoplasia. Indian J Ophthalmol 2017;65:936-41

\section{Figures}




\section{Age distribution of OSSN patients}

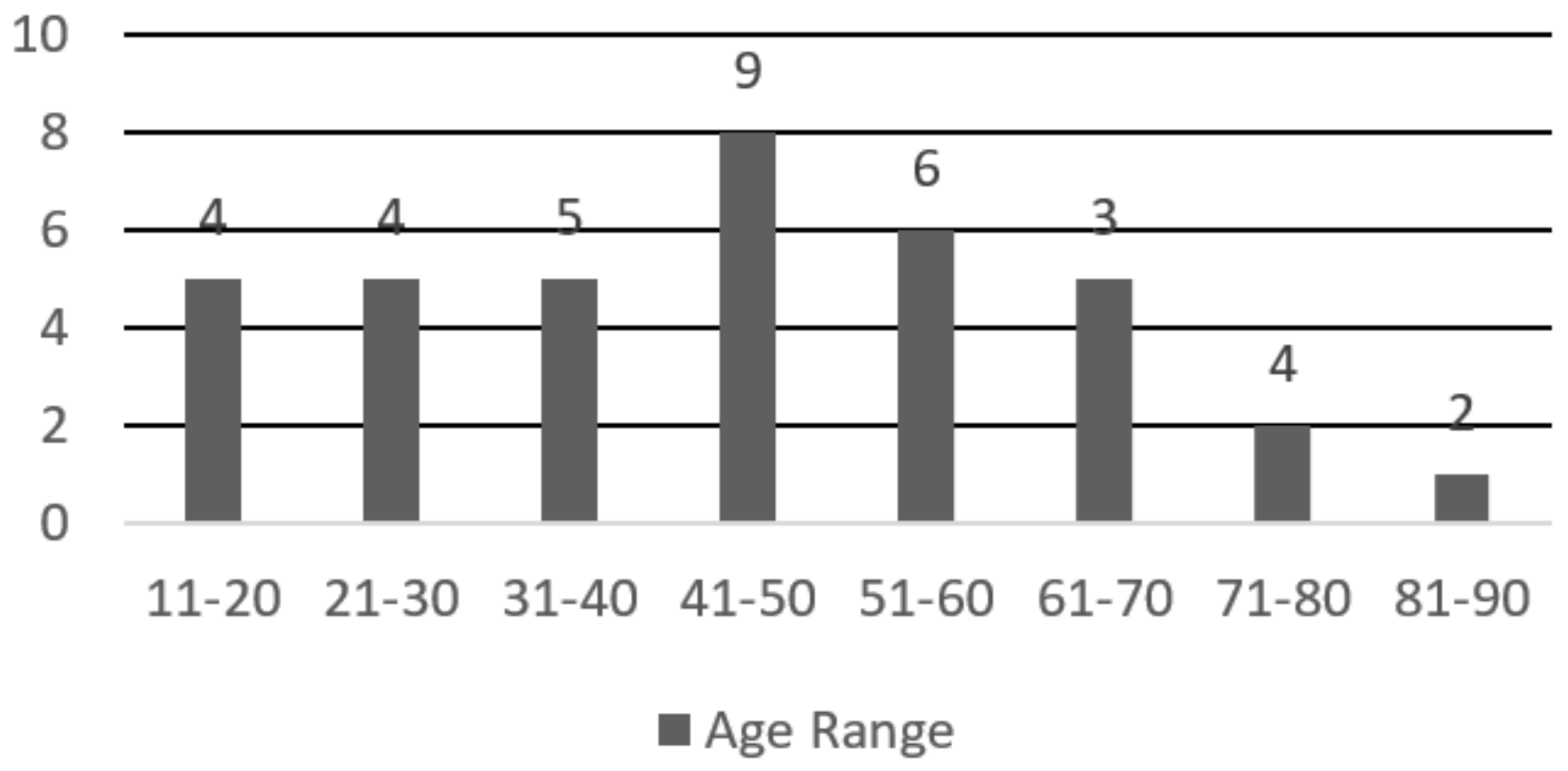

Figure 1

Bar diagram showing Age distribution 


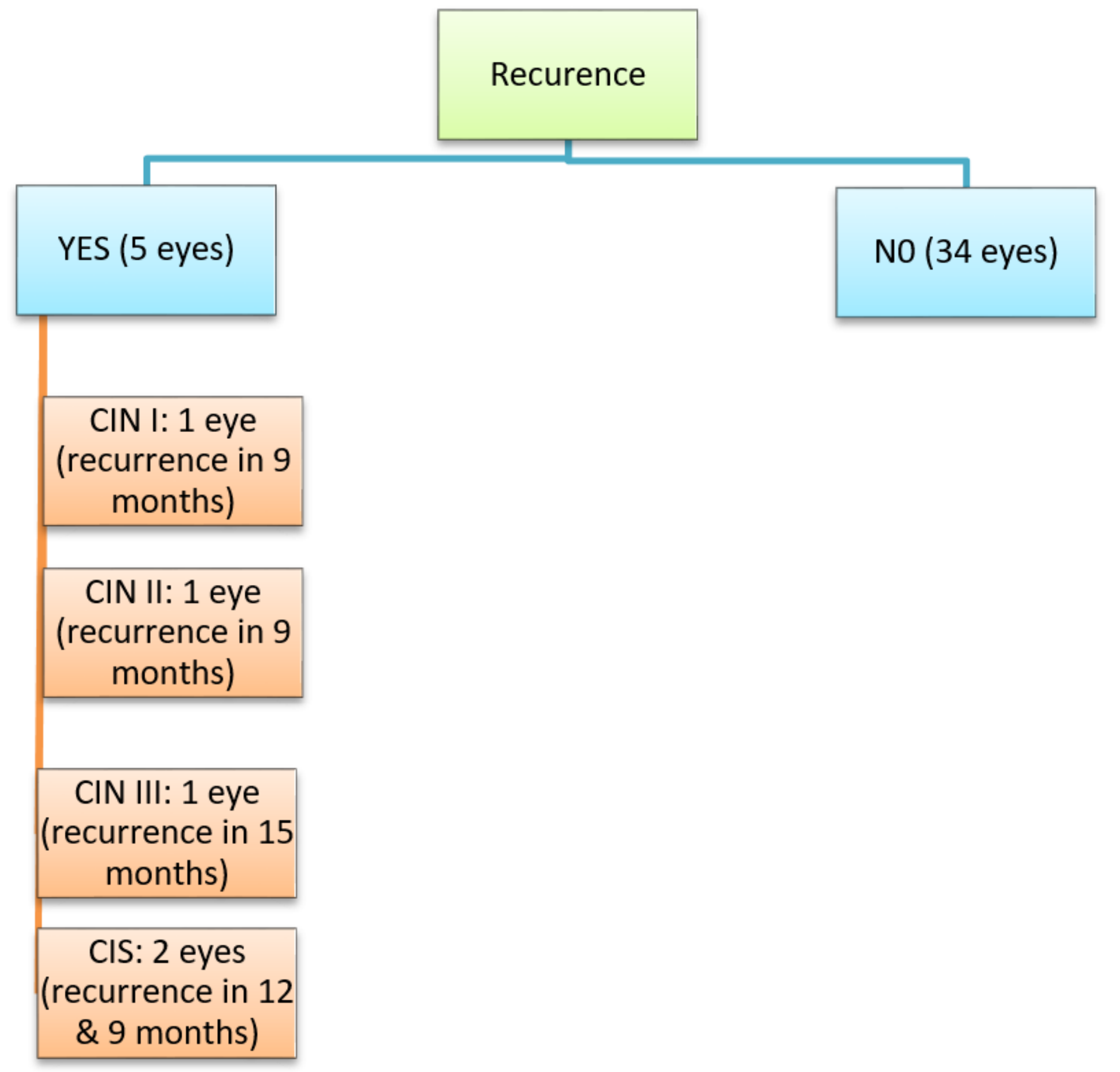

Figure 2

Recurrence pattern 


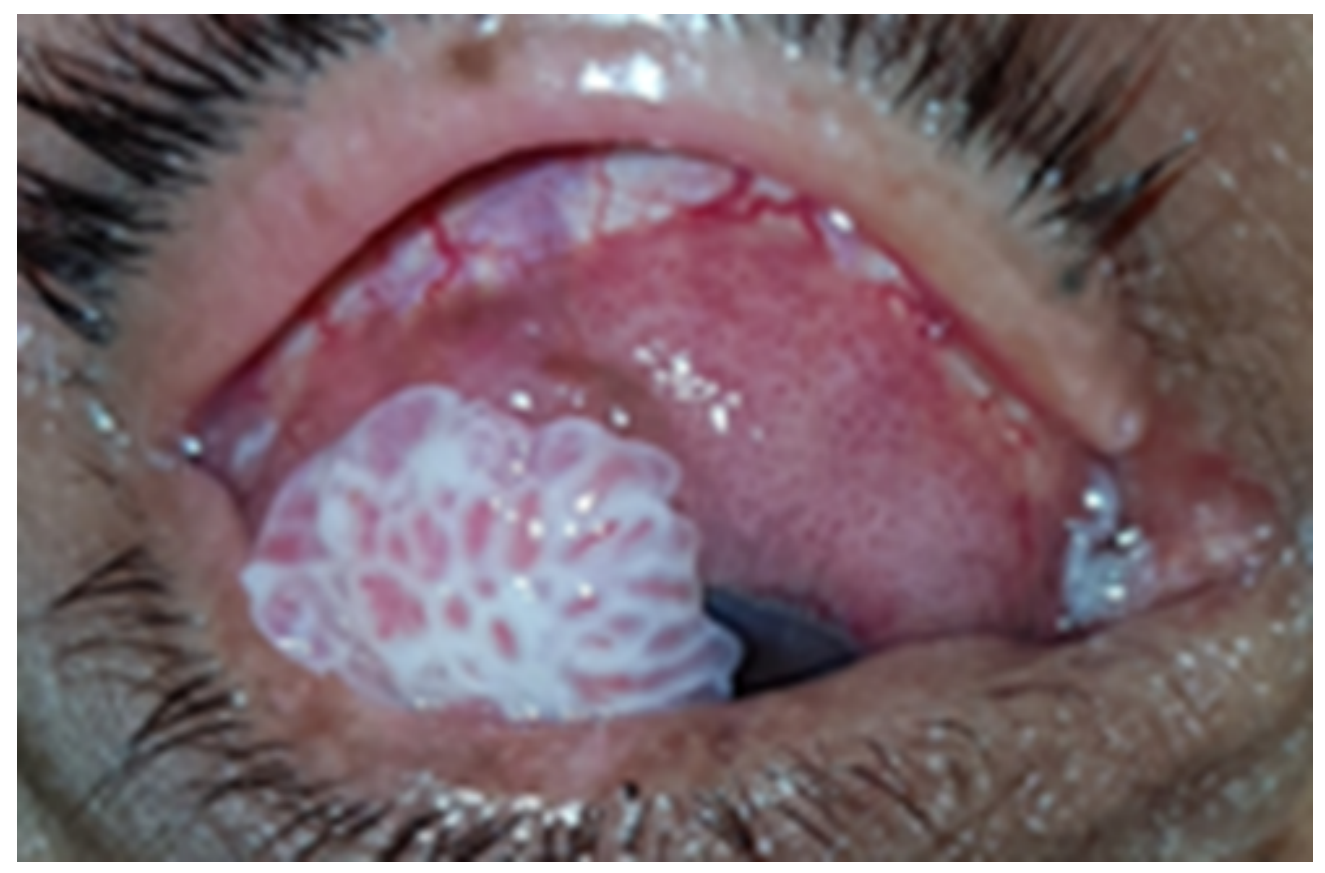

Figure 3

Clinical picture of a large papillary ocular surface squamous neoplasia showing squamous papillomatous growth and leukoplakic growth involving superior bulbar conjunctiva, limbus and cornea

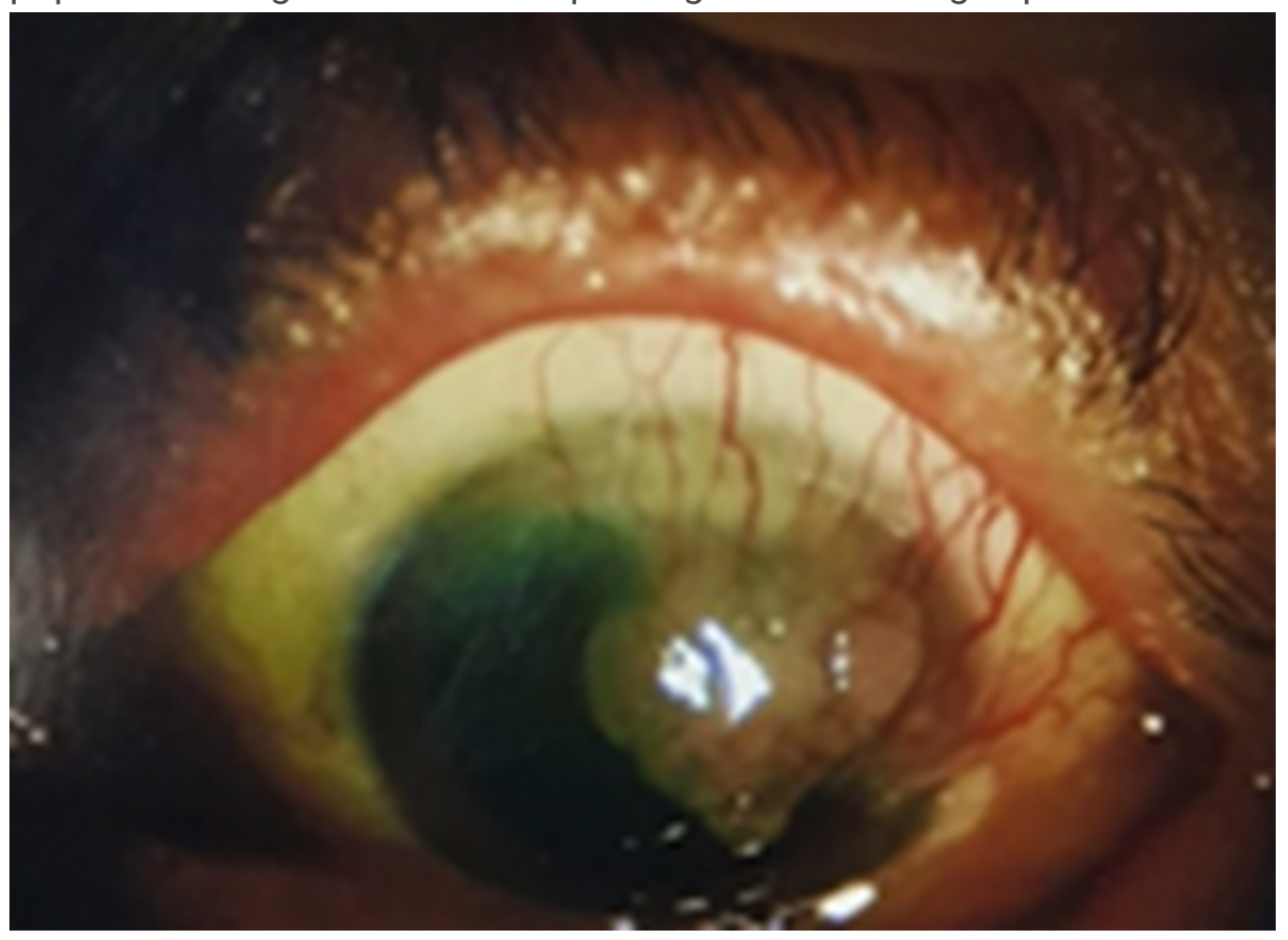

Figure 4

Clinical picture of gelatinous corneal ocular surface squamous neoplasia with feeder vessels from 12 to 3 o'clock position 